\title{
Effect of Material Behaviour on Flow Uniformity over Different Spillway Weir Profiles
}

\author{
J. Dilip singh $\mathbb{D},{ }^{1}$ G. Senthilkumar $\mathbb{D},{ }^{1}$ and Lijalem Mulugeta $\mathbb{D}^{2}$ \\ ${ }^{1}$ Department of Mechanical Engineering, Sathyabama Institute of Science and Technology, Chennai, India \\ ${ }^{2}$ Department of Mechanical Engineering, Faculty of Manufacturing Institute of Technology, Hawassa University, Ethiopia \\ Correspondence should be addressed to Lijalem Mulugeta; lijalem@hu.edu.et
}

Received 23 December 2021; Accepted 12 January 2022; Published 22 February 2022

Academic Editor: V. Vijayan

Copyright $(0) 2022$ J. Dilip singh et al. This is an open access article distributed under the Creative Commons Attribution License, which permits unrestricted use, distribution, and reproduction in any medium, provided the original work is properly cited.

The spillway weir system finds an important application to achieve uniform flow in the open canal stream passages, for irrigation and in many industrial processes, majorly including cooling of reactor components with liquid sodium in prototype fast breeder reactors, process plants, and power industries. The optimal design of weir profile and the velocity of flow over the weir are the critical factors that need to be optimized to minimize flow separation in order to avoid entrainment of gas in flowing liquid, and also, the nonuniform cooling resulted in uneven temperature distributions in many thermohydraulic structures. In this research, the spillway weir profile made from SS-316, SS-304, concrete, and teak wood is compared for optimization of flow uniformity by means of hydraulic experiments conducted on the water-air model and also to investigate the behavior of flow past over the rectangular weir of three different radii $6 \mathrm{~mm}, 6.47 \mathrm{~mm}$, and $7 \mathrm{~mm}$, respectively, and the minimum of $1.2 \%$ flow separation was observed with $6.74 \mathrm{~mm}$ profile, and also, the computational fluid dynamics (CFD) based numerical simulation was performed in the fluid domain to validate the experimental data to attain the flow uniformity when flow past over the spillway weir profile and the results are highlighted. The experimental results on air entrapment, water film thickness, and velocity of water over the weir profile on the perspective of uniformity of flow are also discussed in detail.

\section{Introduction}

In an open water way flow passages and in many chemical processing units, the supposition is that the spillway system paves way to water flow with uniformity for which it is essential to consider the passage length as a function of flow rate. The fascinating idea in the spillway is the profiling of the weir crest. For irrigation, the distribution of water between canals might be effectively functioned with the use of weirs as revealed by Naveen Y. Saad et al. (2016). The spillway design should facilitate that there should not be flow deviation from the crest, and the uniform circumferential flow in the flow passage needs to be always existing. If random design of weir crest is preferred, then separation of flow comes into play at the weir crest, resulting in large impact hit velocity of the falling water due to large-scale entrapment of air inside water. In the view of flow pattern resembling to the shape of the weir crest, the separation of flow needs to be controlled to ensure less impact velocity during hit on the falling surface. Hence, the profile optimization is the basis of the spillway design for ensuring the flow uniformity, and focus is needed for minimum thickness, height, and the inward bend of the weir for cost-effectiveness without sacrificing the safe design of weir profile. For the quality design, the water film thickness has to be measured at various points on the downstream side to identify the impact velocity, which has strong concern on air entrapment. The experimental results for the effect of spillway profile on the air entrapment study are also highlighted. The water film thickness and the drag coefficient are the measured physical quantities. Usually, in a dam, spillway crest is used as a temporary storage of water and also to regulate the water in a controlled way as explained by Chanson and Brattberg [1]. In a controlled spillway, additional head storage of water is possible, whereas in uncontrolled spillway, the excess water flows down due to the energy difference on its own as stated 
by Egemen and Mehmet [2]. Eguchi and Tanaka investigated that an intermediate-type weir profile was employed, and it allowed to store the water for some levels and released beyond a certain limit [3]. Felder and Chanson identified that the spillway flow is of great concern in not only dam but also in many fields including chemical engineering for uniform reactor cooling [4]. The flow pattern of the fluid should ensure no flow separation to avoid air entrapment as experimented by Ghare et al. [5] and Hubert et al. [6], 2010. Kang and Song [7] and Iman and Mehdi (2010) performed that the dissipated energy increased by increasing the degrees of slopes; $k-\varepsilon$ and RNG $k-\varepsilon$ turbulence models are the best numerical models for studying flow uniformity over the spillways [8]. The back-flush Pitot tube with a conductivity probe was used to measure the water velocity and air concentrations in flow over spillways. Jingsen et al. used the three-dimensional unsteady RANS CFD model to predict flow and mixing in jet-mixed water tanks [9], and the same was analyzed by Khayat [10]. Savage and Johnson experimented the free surface entrainment of buoyant particles in a water model of an impeller stirred refining reactor under varying operating conditions; the particle concentration in the bulk water was measured by laser light attenuation [11]. The observed entrainment of particles is explained theoretically, and metallurgical consequences of the findings were discussed. Experiments showed that significant amounts of air particles may be entrained into the water if stirring is applied without purge gas. The SSG Reynolds model simulation indicated that the velocity of flow in cylindrical weirs is proportional to the inclinations of the weirs as revealed by Mehmet Ishak Yuce et al.. Senthilkumar et al. investigated the influence of stream equalizer plates at the upstream water side on the flow uniformity in open channel flow passages [12]. Senthilkumar et al. outlined the impact of spillway weir design on the air entrainment on water in hydraulic structures $[13,14]$. The experiment on the spillway weir optimization for minimization of entrainment of air and bulk air bubbles in water at different fall heights of water over the weir profile on the downstream side of flow passage was analyzed. The more powerful computing techniques made the numerical simulation of solid-fluid interactions in fields like water quality, multiphase flow, entrainment studies, and waste water treatment popular in the few decades. The CFD simulation can be used as both prediction and validation of prototype in complex flow fields. The general procedure in numerical modeling is the translation of physical processes from prototype to the governing equations and solving them with set of mathematical models.

From the literature, it is evident that the profile optimization to achieve flow uniformity is still in the research level only, but the practical requirement of profiles usage is highly significant in many fields including nuclear power reactor cooling. There is a large scope to study the profile optimization and experimental evidence verification for effectiveness of spillway weir profile designs, and the authors have addressed this need in this research by both experimentally and numerically for attainment of uniform flow in the water passage over rectangular spillway weir profile and also the mixing phenomenon of jets with pressure drop characteristics as flow past over the jet breaker plates.

\section{Experimental Procedure}

The schematic of experimental setup is shown in Figure 1. The experimental setup consists of a concrete block of size $1300 \mathrm{~mm} \times 500 \mathrm{~mm} \times 500 \mathrm{~mm}$ over which the entire rectangular model of hydraulic structure for experimentation was built. The model dimensions are $1600 \mathrm{~mm} \times 2176 \mathrm{~mm}$ on $x$ and $y$ directions, respectively, as shown in Figure 2. The structure was covered with transparent Perspex sheets on all the four sides for visualization of flow behavior. The three different rectangular spillway weirs tested were $6 \mathrm{~mm}$, $6.74 \mathrm{~mm}$, and $7 \mathrm{~mm}$ radius at the crest, and the radius $6.74 \mathrm{~mm}$ was considered to be optimized one on the basis of experimental data on minimum flow separation from the crest. In Figure 3, the spillway weir of radius $6.74 \mathrm{~mm}$ made up of wood is placed in between the Perspex sheets, and the gap between upstream water side and weir was $70 \mathrm{~mm}$ and between weir and downstream water side was $40 \mathrm{~mm}$. The total length of rectangular weir is $1580 \mathrm{~mm}$ and height is $241.7 \mathrm{~mm}$, as shown in Figure 4.

The SS-304, SS-316, teak wood, and concrete spillway weir are shown in Figure 5. The major portion of the model is transparent Perspex with provisions for measurement of the water film thickness with fall depth and the entrapment of air from the crest, as shown in Figure 6. A float-type rotameter, with range $0.002-0.015 \mathrm{~m}^{3} / \mathrm{s}$ and accuracy $\pm 0.5 \%$, was fixed regulating the water flow before the weir. An impeller of $4 \mathrm{~kW}$ capacity extracting water from a sump with two valves located one in the inlet and the other in the outlet was incorporated. The purpose of the inlet valve is to attain the required flow rate of the water in the upstream and the water level in the downstream, and fall height was influenced by the outlet valve. A circular pipe of inner diameter $80 \mathrm{~mm}$ was fixed to sump to lift water towards upstream. The designed and fabricated breaker plates made up of SS-304, with size $789 \mathrm{~mm} \times 125 \mathrm{~mm}$, are provided at the bottom of the upstream to distribute water evenly, as shown in Figure 6 . The breaker plate consists of 280 holes, diameter $5 \mathrm{~mm}$ each in a rectangular array of $40 \times 7$. An ultrasonic sensor was used to measure the thickness of water over the weir. In this experimental model, water is used as working fluid at room temperature (i.e., $303 \mathrm{~K}$ ) and enters into the upstream through a single inlet pipe of entry diameter $80 \mathrm{~m}$ to overflow the weir and to the downstream by gravity. The water in the downstream is let out through the holes to a tank and is recirculated by the centrifugal pump through the stream equalizer plate. The flow pattern in the region is influenced by the opposing gravity force and the inertial force. Hence, it is important to simulate the Froude number, which is the ratio of inertial force to the gravitational force. The spillway has been designed by an arc having two different radii. The design of the spillway profile is manufactured by vertical machining centre (VMC). It is made up of teak wood of length $1600 \mathrm{~mm}$, height $241.7 \mathrm{~mm}$, and of 


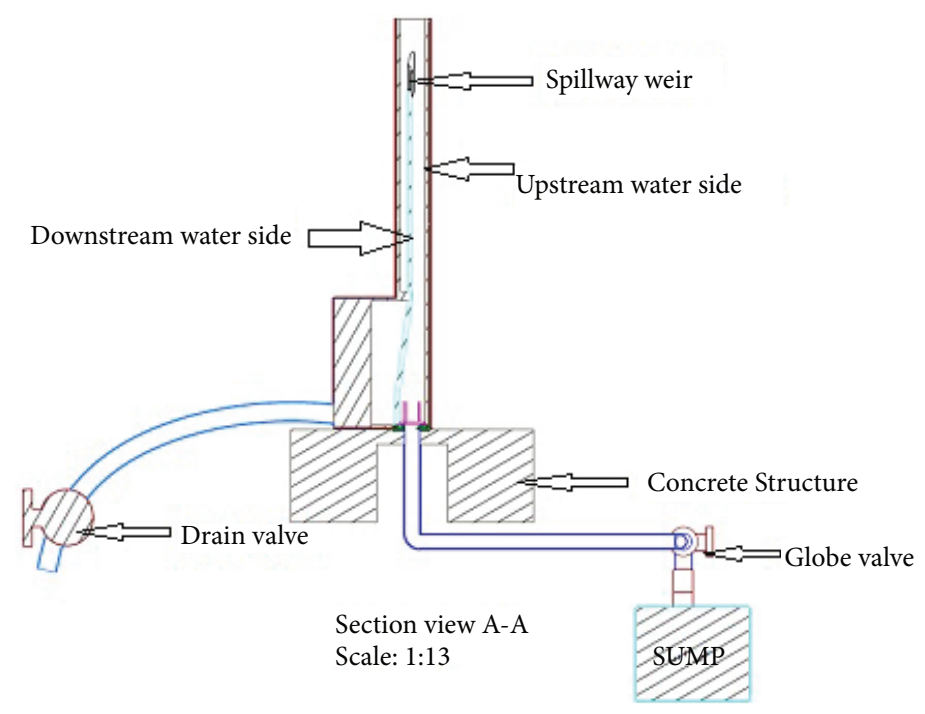

FIGURE 1: Schematic of experimental setup.

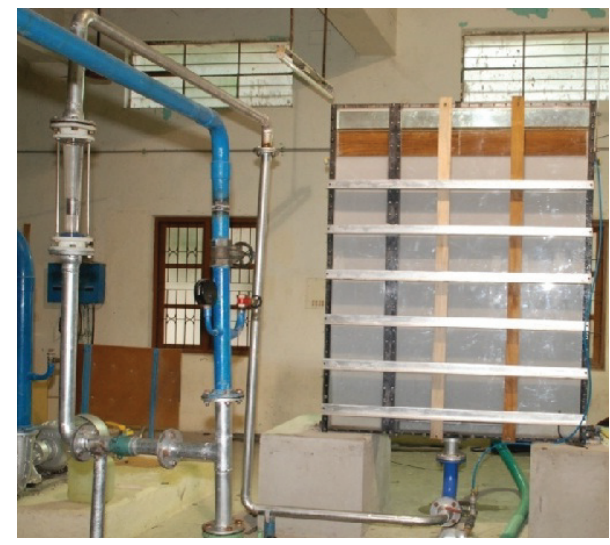

Figure 2: Photographic view of experimental setup.

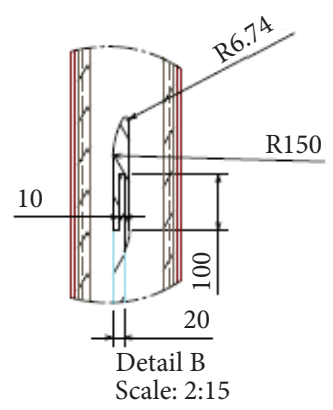

FIgURE 3: Design of spillway weir.

$30 \mathrm{~mm}$ thick. The profile was made smooth to avoid the effect of surface roughness. A globe valve is provided at the inlet pipe to control the flow rate. The hydraulics of the open channel flow passage circuit comprises of the jet discharging into a pool of water with free level. A jet breaker plate, $789 \mathrm{~mm} \times 1250 \mathrm{~mm} \times 5 \mathrm{~mm}$, was placed at the bottom of the upstream water side, as shown in Figure 7. In this plate, the circular holes of $4 \mathrm{~mm}$ diameter were made in a square array. The number of holes was 400 .

\section{Result and Discussion}

This section describes the experimental results on air entrapment and water film thickness and the validation of flow pattern with CFD simulation as follows.

3.1. Air Entrapment. The flow behavior of water along the rectangular spillway weir is presented in this section, as shown in Figure 8. The air bubbles dragged into the downstream up to certain depth, referred as penetration depth; then, it is decelerated (due to the friction of the water present in the downstream) as it continues its travel towards the bottom of the collector. The uncertainty error of the air entrapment tester was $\pm 0.5 \%$. The presence of air in water was estimated as a function of penetration depth for flow ranges from 0.002 to $0.01 \mathrm{~m}^{3} / \mathrm{s}$. It is observed that no flow deviation occurred at low flow rate range of $0.002-0.005 \mathrm{~m}^{3} /$ $\mathrm{s}$ since laminar flow conditions exist up to this discharge range. Thus, it is clear that the designed rectangular profile of radius of curvature $6.74 \mathrm{~mm}$ was satisfactory at such flow conditions. It is observed that air entrapment takes place for the flow rates of $0.006-0.01 \mathrm{~m}^{3} / \mathrm{s}$ as evident from Wilhelms et al., which stated that the air entrapment is less if the flow rate is low [15]. Hence, it was inferred that the air entrapment is directly proportional to the flow rate as investigated by Turan et al. [16]. The increase of fall height from zero increased the velocity of water impinged on the weir surface. Due to this, the free surface at the impingement point deformed and led to the air entrapment. The entrapment was least and found to be within $150 \mathrm{~mm}$ for flow rate range of $0.002-0.005 \mathrm{~m}^{3} / \mathrm{s}$ and beyond $0.05 \mathrm{~m}^{3} / \mathrm{s}$, up to $0.01 \mathrm{~m}^{3} / \mathrm{s}$, and the air depth in water was in the range of $160-375 \mathrm{~mm}$ due to large disturbance inertia force. At higher velocities of $0.01 \mathrm{~m} / \mathrm{s}$ as measured by the propeller turbine type anemometer (in the upper part of the downstream), the water friction is mere sufficient to drag air bubbles against the buoyancy effect. However, as the water velocity is reduced (in the bottom part of the downstream), 


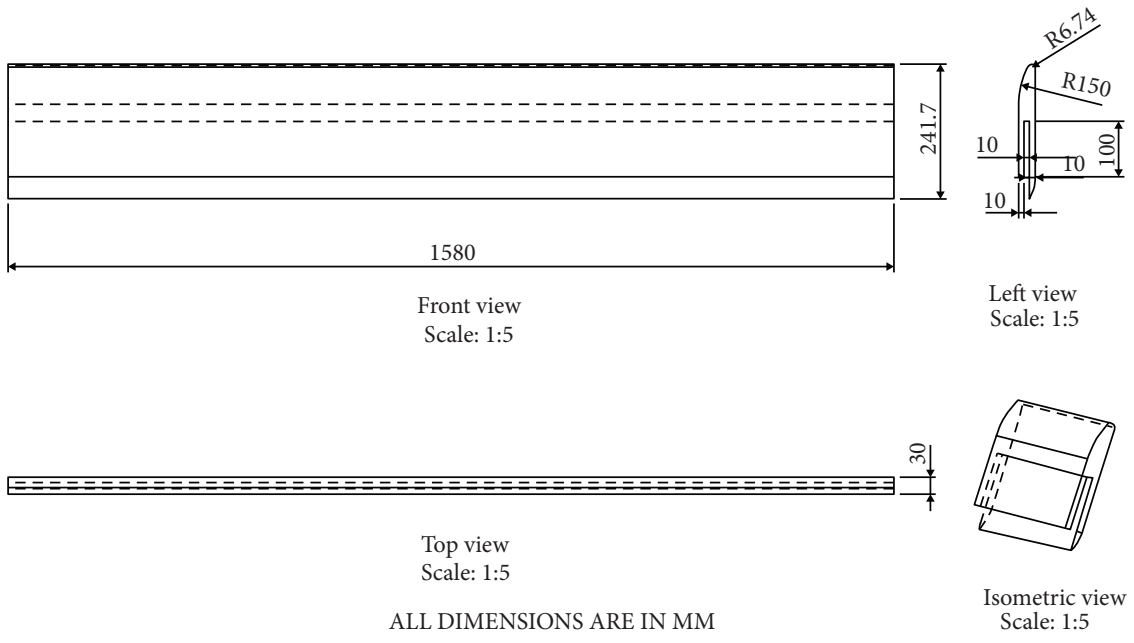

FIGURE 4: Elevation and plan of rectangular weir.

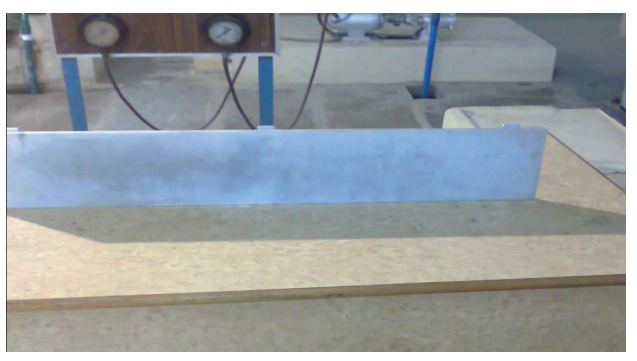

(a)

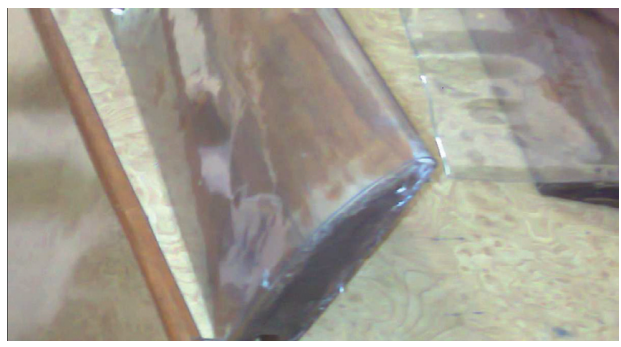

(c)

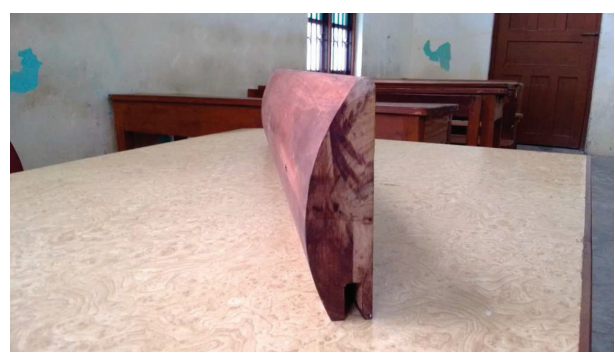

(b)

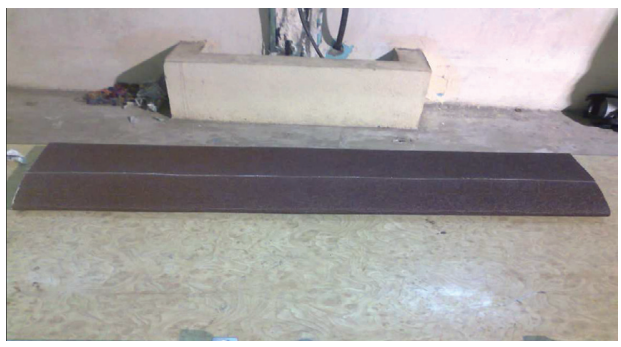

(d)

FIgURE 5: Spillway weir materials. (a) Concrete profile. (b) Teak wood profile. (c) SS-304-coated profile. (d) SS-316-coated profile.

the air bubbles are able to overcome the water drag and travels back to the free surface from where they are entrained $[17,18]$. It is seen that all the visible air bubbles, bubble out to the free surface. It can be seen that the penetration depth exhibits a nonmonotonic relation with fall height.

3.2. Film Thickness and Drag Coefficient. The water film thickness past over the rectangular weir is measured with an ultrasonic sensor with accuracy $\pm 0.2 \%$. The thickness was measured along the length of weir at every $200 \mathrm{~mm}$ along $x$ axis, as shown in Figure 9, and the same was validated with the following analytical expression for flow over rectangular weirs:

$$
q=0.415 x(L-0.2 h) x h^{3 / 2} x(2 g)^{1 / 2},
$$

where $q$ is the flow rate in $\left(\mathrm{m}^{3} / \mathrm{s}\right), L$ is the perimeter of the weir $(\mathrm{mm}), h$ is the water film thickness over the spillway $(\mathrm{mm})$, and $g$ is the acceleration due to gravity $\left(\mathrm{m} / \mathrm{s}^{2}\right)$, and the compared results are also given in Table 1. From the experimental result, it was inferred that more flow uniformity was found at centre of weir for which $x$-locations was $800 \mathrm{~mm}$ and $1000 \mathrm{~mm}$. The figure shows the data for weir radius of $6.47 \mathrm{~mm}$, which was optimized one as revealed from air entrapment studies discussed in previous Section 4 . It can be seen that the least value of film thickness during $0.002-0.01 \mathrm{~m}^{3} / \mathrm{s}$ flow rate. This value decides the tolerance on the evenness of the spillway weir. Though the increase in film thickness was quiet natural with flow rate, the contribution at the both ends of the weir for the variation in water film thickness was noticed to be less significant. 


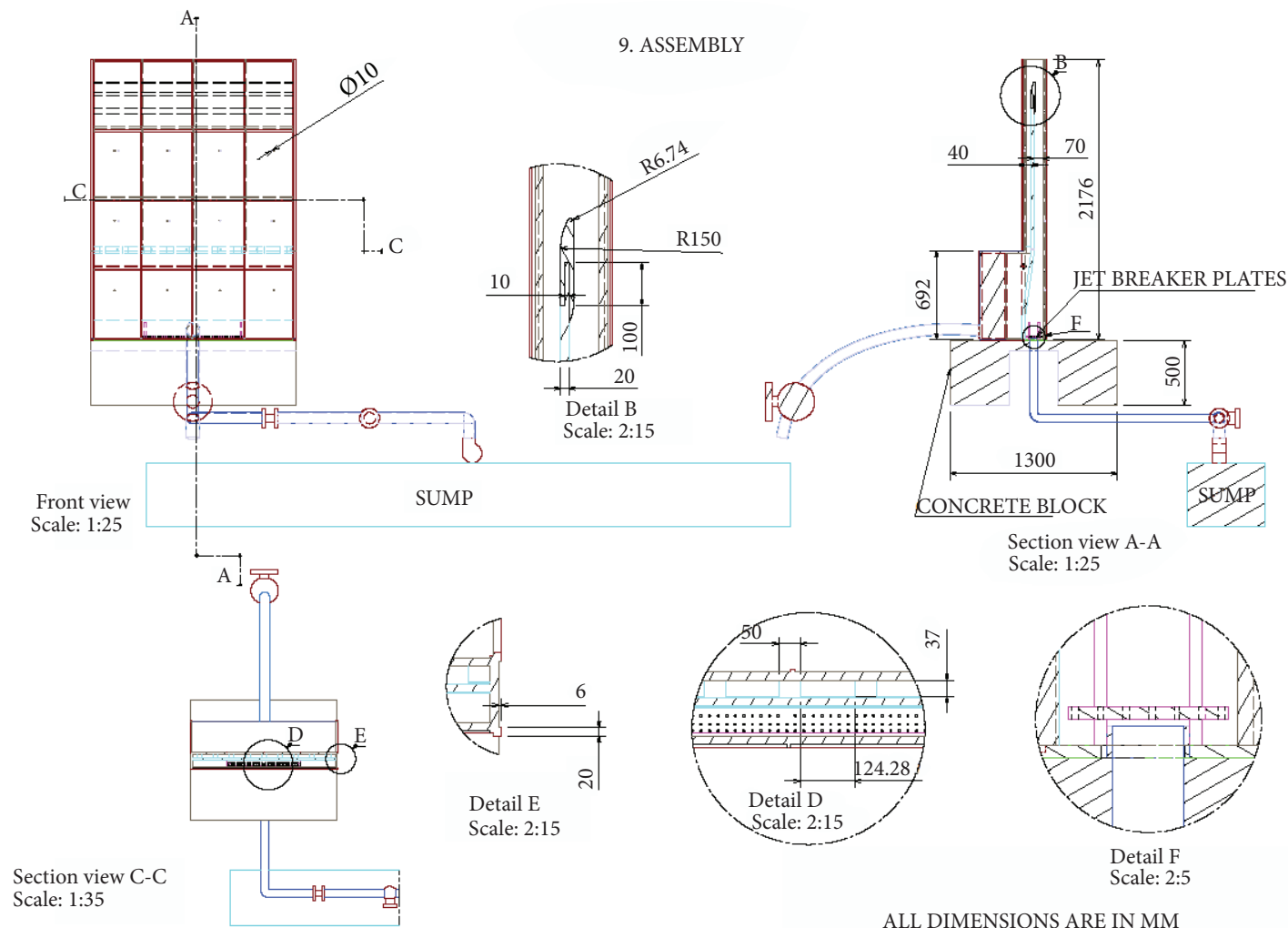

FIGURE 6: Assembly of experimental setup.
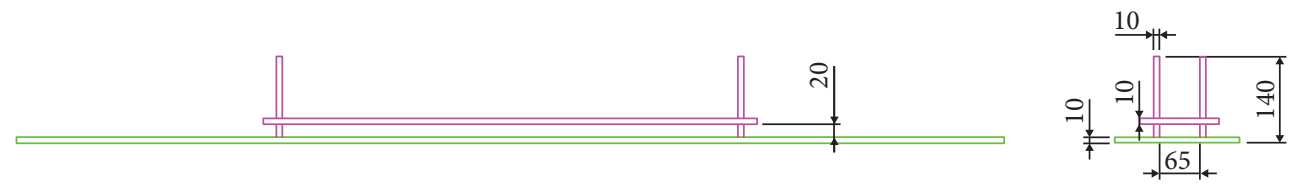

Front view

Left view

Scale: $1: 5$

Scale: 1:5

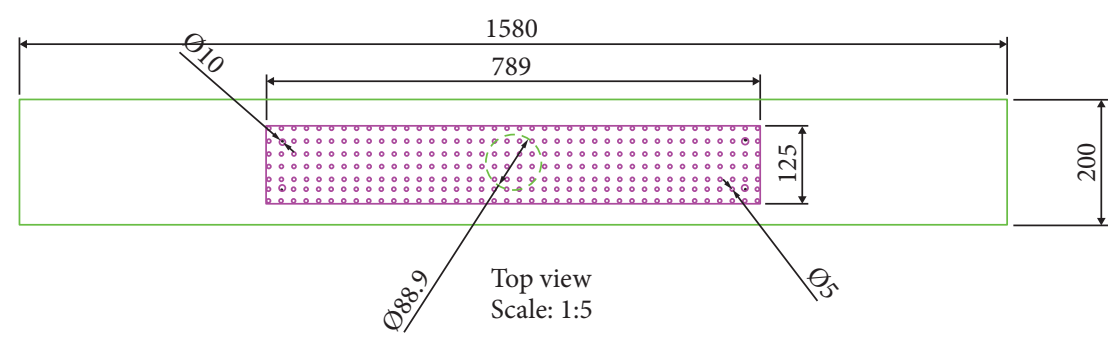

ALL DIMENSIONS ARE IN MM

FIgURE 7: Design of the jet breaker plate.

3.3. Numerical Simulation for Volume Fraction. The computational fluid dynamics (CFD) is a procedure to estimate the various flow parameters in the domain created. The NavierStokes equation is the basis for all the CFD simulations such as temperature, velocity, density, and pressure contours executed within the flow domain. The tetra mesh created by GAMBIT, a preprocessor for FLUENT, is shown in Figure 10.

The computational model of weir is shown in Figure 11. The flow uniformity in water was simulated numerically using the CFD code, FLUENT, and validated with the experimental data, as shown in Figure 12.

Boundary conditions are as follows:

(i) The distilled water was at uniform temperature of $27^{\circ} \mathrm{C}$

(ii) The friction at the flow entry was negligible

(iii) The flow rate varied from $0.02-0.1 \mathrm{~m}^{3} / \mathrm{s}$ 


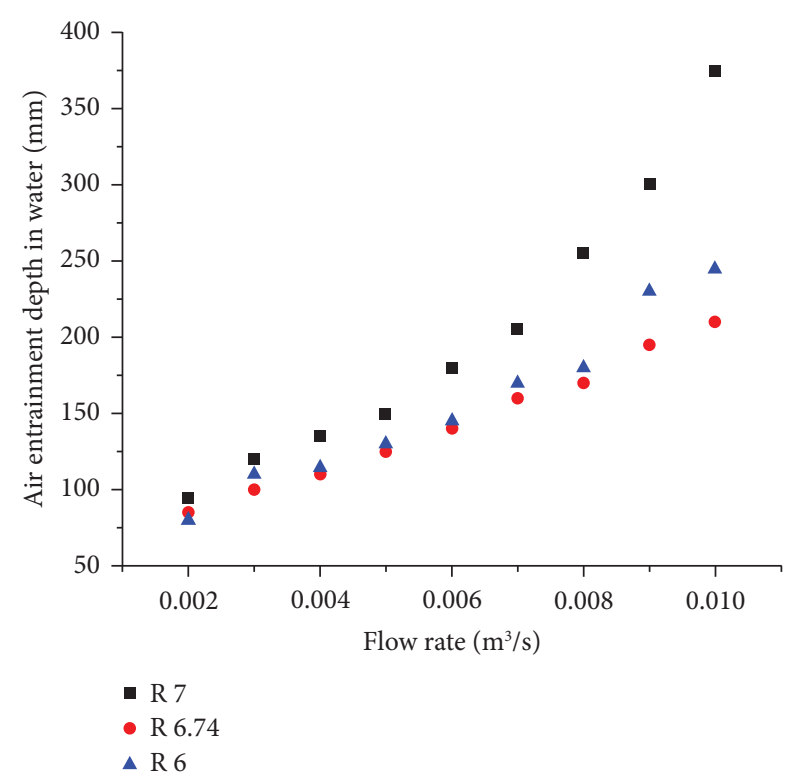

Figure 8: Air entrapment depth in water for different flow rates.

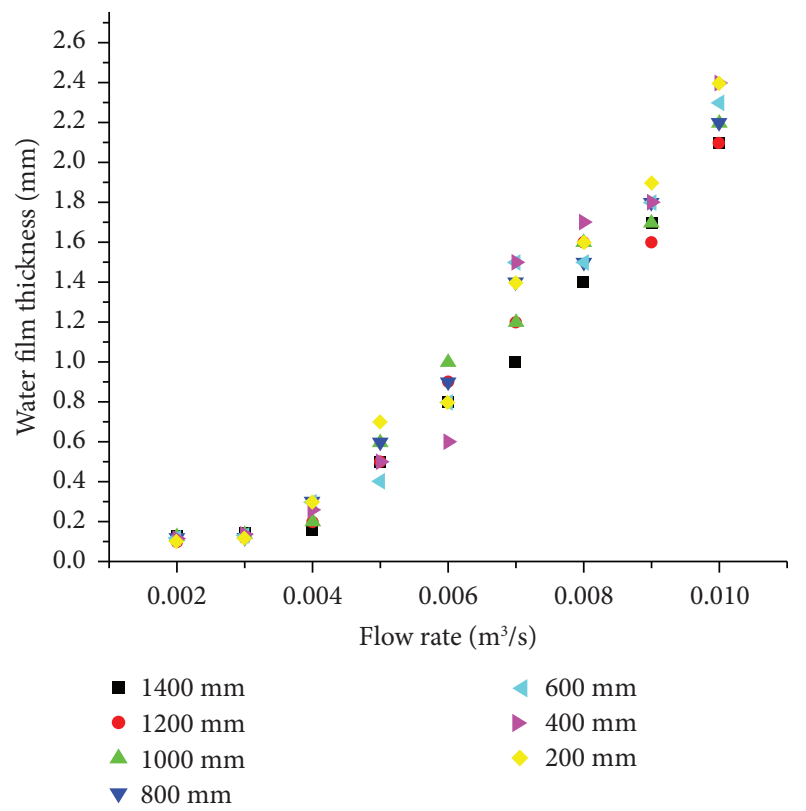

FIGURE 9: Water film thickness along the length of weir of $R 6.47 \mathrm{~mm}$.

TABLE 1: Thermophysical properties.

\begin{tabular}{lcccc}
\hline Fluid/properties & $\begin{array}{c}\rho \\
\mathrm{kg} / \mathrm{m}^{3}\end{array}$ & $\begin{array}{c}C_{P} \\
\mathrm{~J} / \mathrm{kg} \mathrm{K}\end{array}$ & $\begin{array}{c}K \\
\mathrm{~W} / \mathrm{m} \mathrm{K}\end{array}$ & $\begin{array}{c}\mu \\
\mathrm{Ns} / \mathrm{m}^{2}\end{array}$ \\
\hline Air & 1.1277 & 1007 & 0.02701 & $2.837 e-05$ \\
Water & 1000 & 4200 & 0.5 & $0.28 e-03$ \\
\hline
\end{tabular}

(iv) 3D, axis symmetric, pressure-based model with second-order upwind scheme

(v) Convergence accuracy was fixed at $10^{-5}$ between successive iterations

(vi) Tetra mesh with skewness 0.5 was assigned for fluid domain

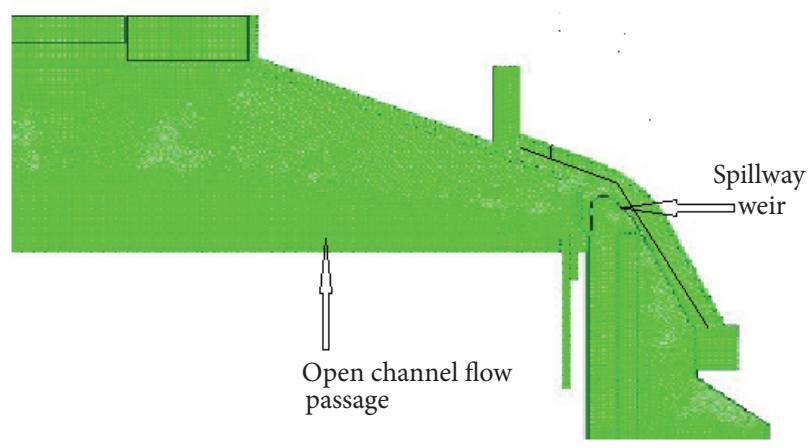

Figure 10: Mesh generation in the fluid domain.

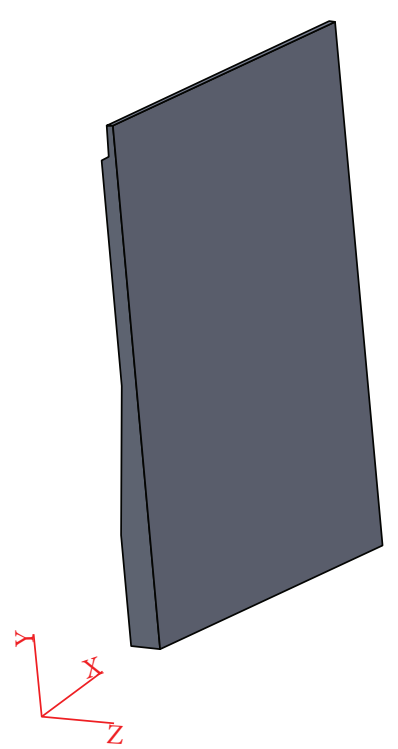

FIgURE 11: Computational domain of weir for flow uniformity.

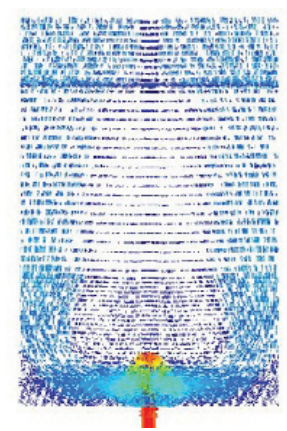

Figure 12: Velocity vector field on upstream water side.

The total mesh elements created was 68,000 with mesh type of tetrahedron. The initial conditions were $0.1 \mathrm{~m} / \mathrm{s}$ velocity with $38 \%$ porous stream plates for uniform distribution of water in the flow passage. The necessary factors to be satisfied are minimum flow deviation and large water film thickness over the crest of the profile tested. The secondorder upwind pressure model was employed for this study. The experiments as well as the CFD studies were done at atmospheric pressure of 1 bar and at a temperature for $27^{\circ} \mathrm{C}$. When the water flow rate reduced from $0.01 \mathrm{~m}^{3} / \mathrm{s}$ to 
$0.002 \mathrm{~m}^{3} / \mathrm{s}$, the volume fraction (VF) of air also reduced from $29.5 \%$ to $13.4 \%$, and the reduction was due to the air entrapment as discussed in Section 4 . The percentage variation of CFD results was $1.2 \%$ and $0.9 \%$ for these flow rates, respectively. Since the focus of this research was to estimate the VF of air in water, only hydraulic considerations were adopted, and subsequently, the Navier-based continuity and momentum equations were solved for this uneven flow field. The flow mal distribution index (MI) was analyzed numerically using CFD code FLUENT at the flow ranges from 0.002 to $0.015 \mathrm{~m}^{3} / \mathrm{s}$. The MI determines the deviation of actual velocity from the mean velocity of flow of water in the upstream flow passage.

$$
\mathrm{MI}=\left[\left\{\left(\sum V \text { mean }-V_{i}^{2}\right)\right\} / n\right]^{0.5} / V \text { mean, }
$$

where $V_{\text {mean }}$ is the mean velocity of water in the annulus, $V_{\mathrm{i}}$ is the velocity component in $y$-direction at any point $i$, and $n$ is the number of positions on the flow passage. It can be evident that the MI value is zero at uniform flow or minimum impact velocity of water and reached maximum where the separation of flow is maximum.

\section{Conclusion}

The spillway profile has been tested for entrapment of air bubbles in water for flow rate from 0.002 to $0.015 \mathrm{~m}^{3} / \mathrm{s}$. It is found that the designed rectangular weir profile of radius $6.74 \mathrm{~mm}$ gave less entrapment of air bubbles of $80 \mathrm{~mm}$ at different $x$ locations lengthwise at uniform flow conditions. For higher flow rate of $0.01 \mathrm{~m}^{3} / \mathrm{s}$, the entrapment was found to be as high as $250 \mathrm{~mm}$, and hence, profiles with radii $6 \mathrm{~mm}$ or $7 \mathrm{~mm}$ were not suggested for air entrapment studies. Hence, it is preferable to use profile with radius $6 \mathrm{~mm}$ for the above flow rate for air entrapment studies. From the measurements, the water film thickness which accelerates the flow downstream of spillway under gravity was also calculated. From the results, it was concluded that the profile gives comparatively higher values of film thickness from the crest of the weir than at the downstream indicated minimum flow separation from the weir crest. Based on experimental and CFD simulation, SS316 was found to be the best for flow characteristics. This gives symmetry in flow passage at stabilized water free level, resulting in minimum entrapment of air in water. The CFD results also validated with the experimental data, and it was found that on the aspect of flow uniformity, the rectangular profile of $6.74 \mathrm{~mm}$ radius yielded minimum flow separation and maximum water film thickness comparatively.

\section{Data Availability}

The data used to support the findings of this study are included within the article and are available from the corresponding author upon request.

\section{Disclosure}

It was performed as a part of the Employment Hawassa University, Ethiopia.

\section{Conflicts of Interest}

The authors declare that there are no conflicts of interest.

\section{Acknowledgments}

The authors would like to thank the Sathyabama Institute of Science and Technology for their excellent support for the submission of their studies.

\section{References}

[1] H. Chanson and T. Brattberg, "Experimental study of the airwater shear flow in a hydraulic jump," International Journal of Multiphase Flow, vol. 26, no. 4, pp. 583-607, 2000.

[2] A Egemen and B Mehmet, "Comparison of stepped and smooth spillway effects and re-aeration," WaterSA, vol. 36, no. 3, pp. 309-314, 2010.

[3] Y. Eguchi and N. Tanaka, "Fluid elastic vibration of flexible overflow weir," JSME International Journal, Series III, vol. 33, pp. 1-6, 1990.

[4] S. Felder and H. Chanson, "Air-water flow measurements in a flat slope pooled stepped waterway," Canadian Journal of Civil Engineering, vol. 40, no. 4, pp. 361-372, 2013.

[5] A. D Ghare, V. A Mhaisalkar, and P. D Porey, "An approach to optimal design of trapezoidal labyrinth weirs world applied sciences journal," vol. 3, no. 6, pp. 934-938, 2008.

[6] H. Chanson, "Predicting oxygen content downstream of weirs, spillways and waterways," Civ. Engrs Wat. Marit. and Energy, UK, vol. 112, pp. 20-30, 2010.

[7] H.-S. Kang and C.-H. Song, "Cfd analysis of turbulent jet behavior induced by a steam jet discharged through a vertical upward single hole in a subcooled water pool," Nuclear Engineering and Technology, vol. 42, no. 4, pp. 382-393, 2010.

[8] N. R. Iman and T. Mehdi, "An investigation of flow energy dissipation in simple stepped spillways by numerical model," European Journal of Scientific Research, vol. 47, no. 4, pp. 544-553, 2010.

[9] M. A. Jingsen, R. T. Oberai, J. D. Lahey, and A. Drew, "Modeling air entrainment and transport in a hydraulic jump using two-fluid RANS and DES turbulence models," Heat and Mass Transfer, vol. 47, no. 8, pp. 911-919, 2012.

[10] K. H. Khayat, "Optimization and performance of airentrained, self-consolidating concrete," Materials Journal, vol. 97, pp. 526-535, 2000.

[11] B. M. Savage and M. C. Johnson, "Flow over ogee spillway: physical and numerical model case study," Journal of $\mathrm{Hy}$ draulic Engineering, vol. 127, no. 8, pp. 640-649, 2001.

[12] G. Senthilkumar, A Anderson, and S Lakshmi, "Cause of flow distributor on open water way stream passages velocity comparisions," International Journal of Ambient Energy, vol. 41, no. 5, pp. 547-549, 2018.

[13] G. Senthilkumar and A. Anderson, "Study of flow pattern in open channel flow passages," International Journal of Ambient Energy, vol. 40, no. 5, pp. 482-489, 2017.

[14] G. Senthilkumar and S. S Lakshmi, "Bubble dynamic behavior of air water two phase flow mixing in hydraulic structures," International Journal of Ambient Energy, vol. 42, no. 5, pp. 505-507, 2018.

[15] C. Wilhelms, J. S. Gulliver, J. T. Ling, and R. S. Ling, "Gas transfer, cavitation, and bulking in self-aerated spillway flow," Journal of Hydraulic Research, vol. 43, no. 5, pp. 532-539, 2005. 
[16] C. Turan, M. S. Politano, P. M. Carrica, and L. Weber, "Water entrainment due to spillway surface jets, int," Journal of Computational Fluid Dynamics, vol. 21, no. 3, pp. 137-153, 2007.

[17] N Yousif and E Fattouh, "Hydraulic characteristics of flow over weirs with circular openings," Ain Shams Engineering Journal, vol. 8, no. 4, pp. 515-522, 2016.

[18] M. I. Yuce, A. A. H. Al-Babely, and M. A. Al-Dabbagh, "Flow simulation over oblique cylindrical weirs," Canadian Journal of Civil Engineering, vol. 42, no. 6, pp. 389-407, 2015. 